Supporting Information

\title{
A Trickle Flow Aided Atomic Layer Deposition (ALD) Strategy for Ultrathin Molybdenum Disulfide $\left(\mathrm{Mos}_{2}\right)$ Synthesis
}

\author{
Junjie Yang \#, Lei Liu*,\#
}

School of Mechanical Engineering, Southeast University, Nanjing 211189,

People's Republic of China

* Corresponding author, email: liulei@seu.edu.cn

\# These authors contributed equally to this work 

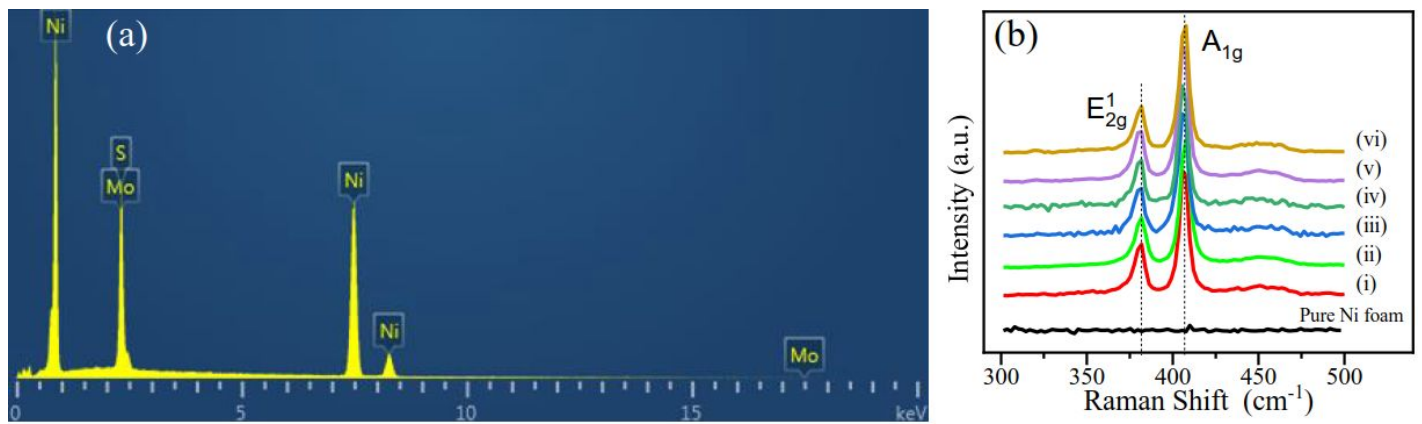

Figure S1 (a) EDS spectra of Ni foam after 50 ALD cycles. (b) The Raman spectra for Ni foam and $\mathrm{Ni}$ foam after the ALD process at (i-vi)-position in Figure 1.
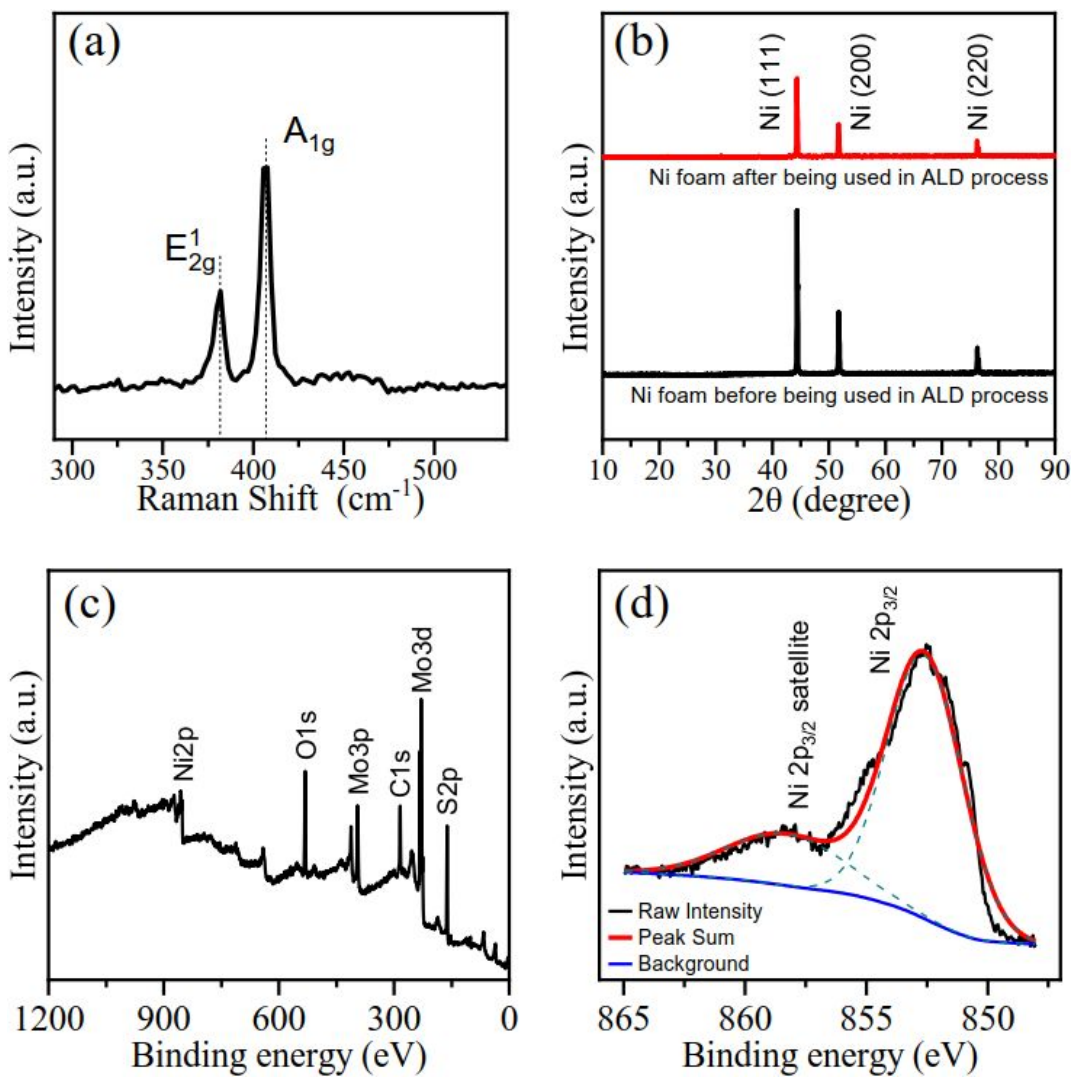

Figure S2 (a) Raman spectroscopy, (b) XRD spectroscopy, (c) complete XPS spectrum, and (d) Ni2p orbital spectra of the sample of Ni foam after ALD process. 


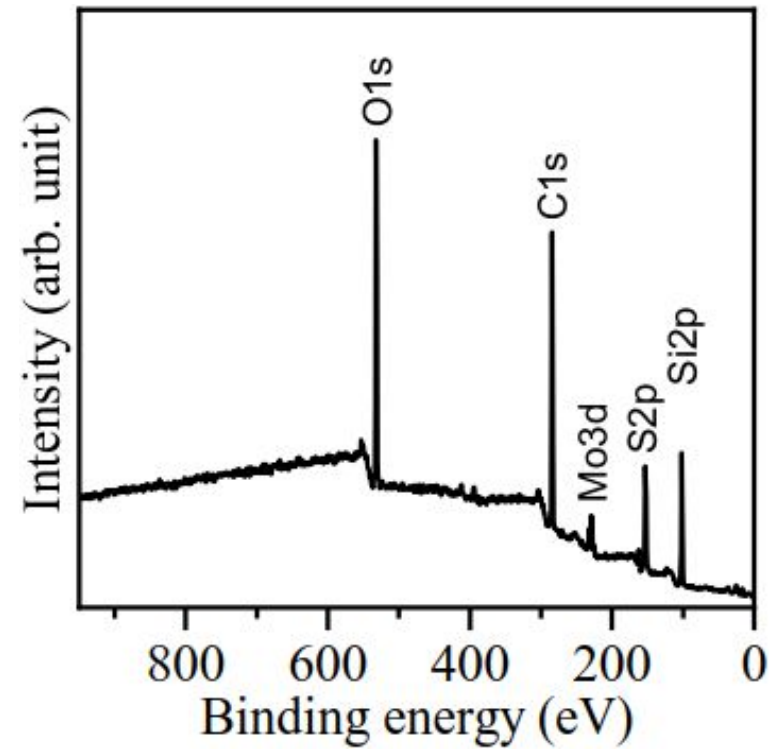

Figure S3 The survey scan of X-ray photoelectron spectra (XPS) for as-deposited ALD $\mathrm{MoS}_{2}$ film.
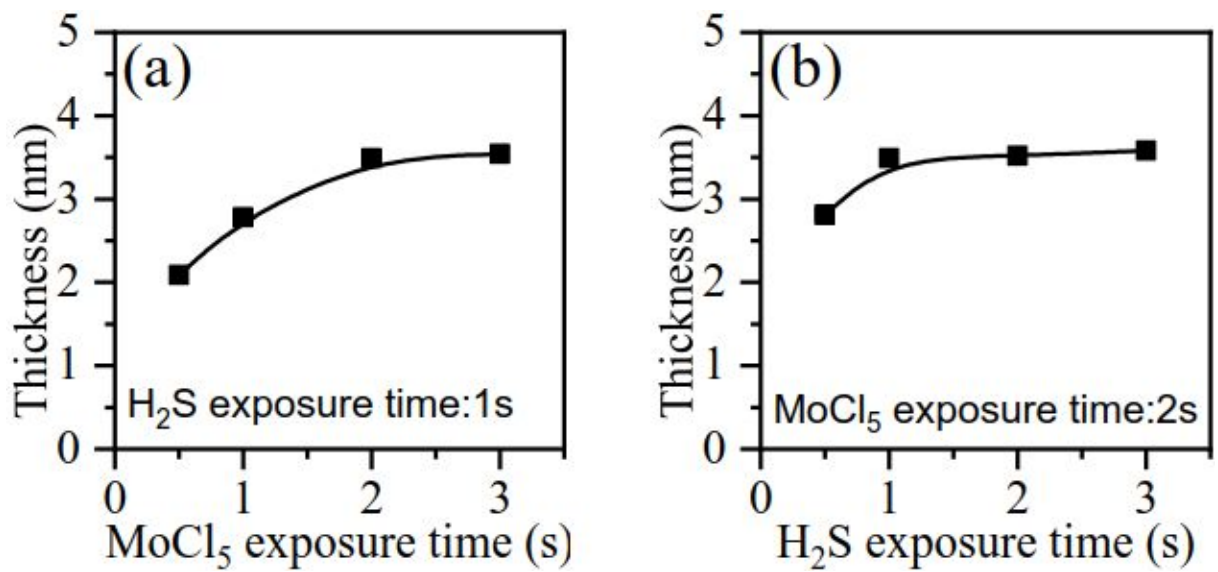

Figure S4 Relationship between thickness of $\mathrm{MoS}_{2}$ and exposure time of (a) $\mathrm{MoCl}_{5}$ and (b) $\mathrm{H}_{2} \mathrm{~S}$ for $50 \mathrm{ALD}$ cycles at $460{ }^{\circ} \mathrm{C}$. The curves are drawn for guiding the eye. 


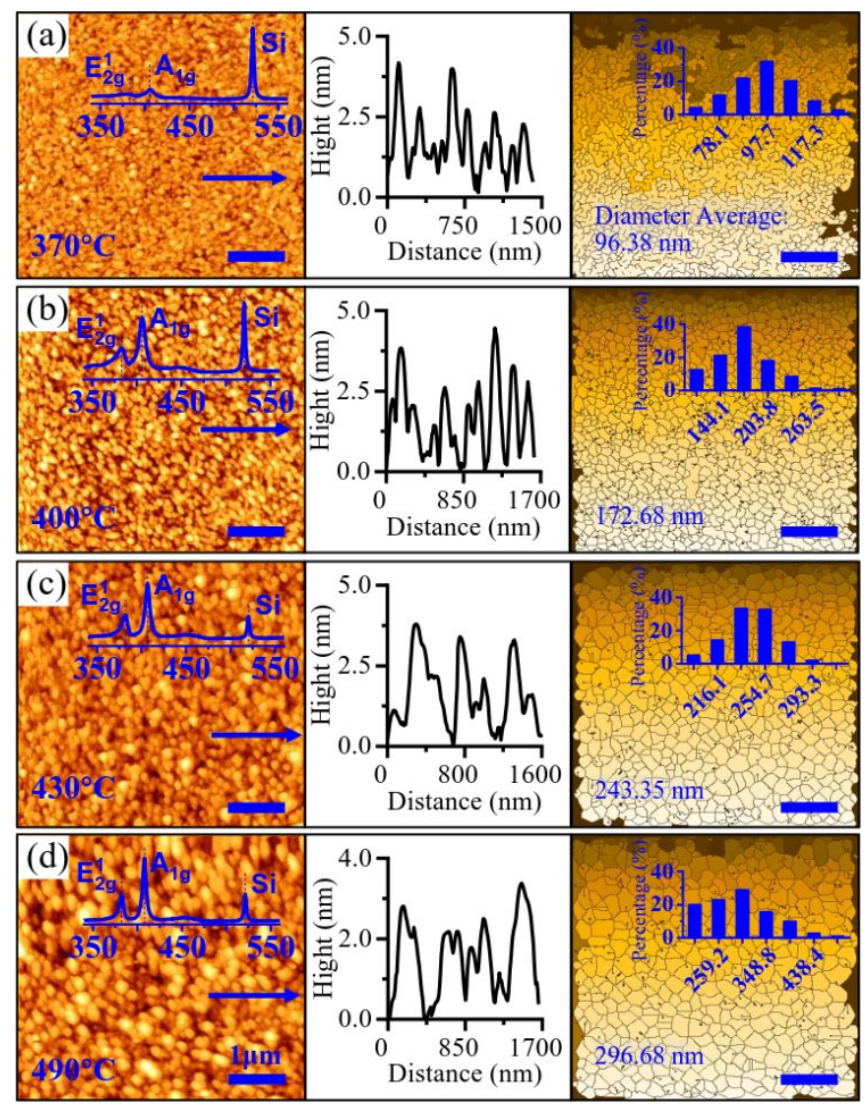

Figure S5 (a-d): characterization results for the samples obtained at $370^{\circ} \mathrm{C}, 400^{\circ} \mathrm{C}, 430^{\circ} \mathrm{C}$, and $490^{\circ} \mathrm{C}$, respectively. For each one (from left to right): AFM images, line profiles, grain images. The films were deposited with 50 cycles and $1 \mathrm{~mm}$ thick Ni foam with its gap of $2 \mathrm{~mm}$. The insets in AFM images show their corresponding Raman spectra. The horizontal axis is the Raman shift $\left(\mathrm{cm}^{-1}\right)$. The insets in the grain images show the histogram of grain distribution. The vertical axis is in percentage (\%), and the horizontal axis is grain diameter $(\mathrm{nm})$. All scale bars are $1 \mu \mathrm{m}$.

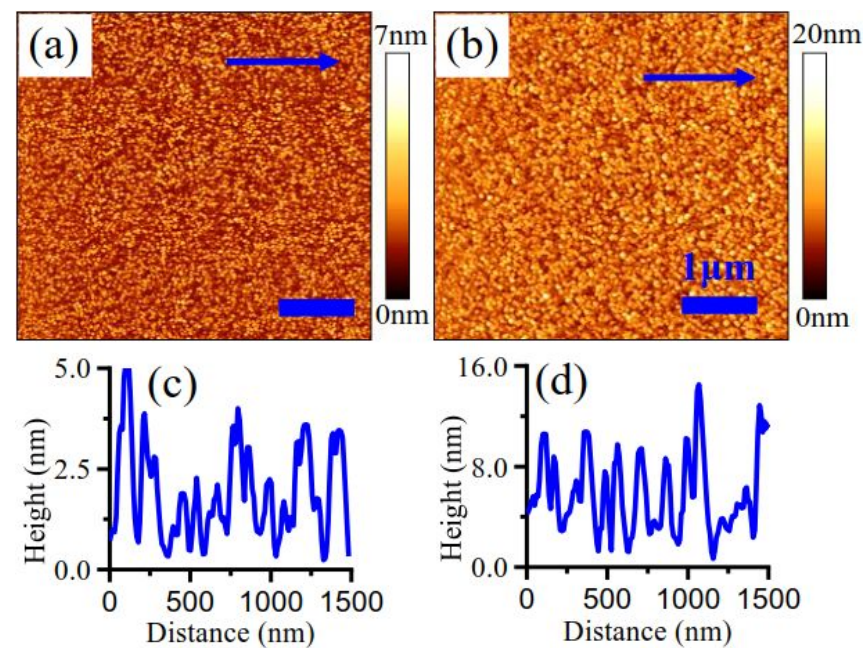

Figure S6 (a-b) AFM images of $\mathrm{MoS}_{2}$ films deposited on $\mathrm{SiO}_{2} / \mathrm{Si}$ substrates with 10 and 50 cycles using normal ALD at $460^{\circ} \mathrm{C}$. The scale bar is $1 \mu \mathrm{m}$. (c-d) is the corresponding AFM line profiles. 

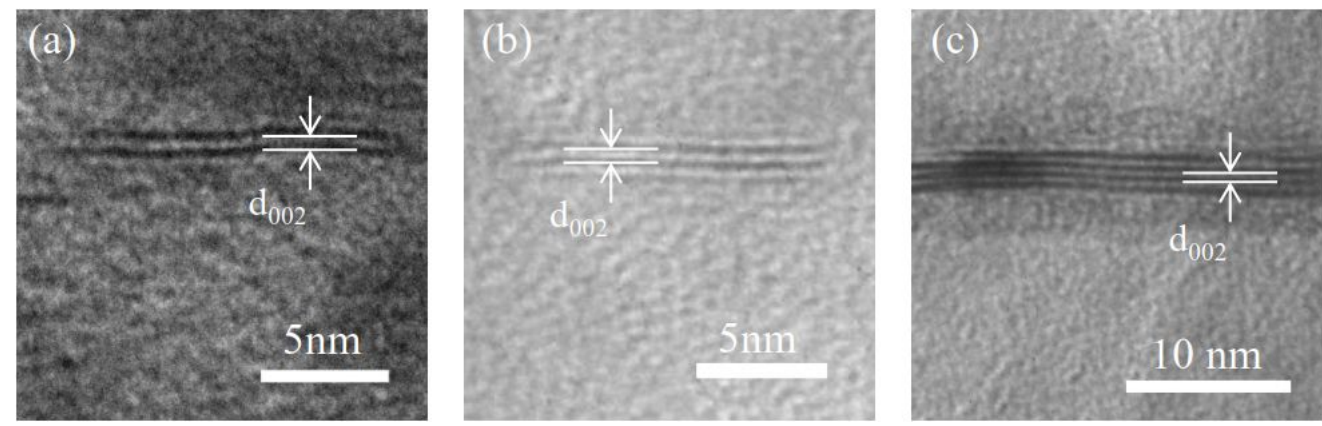

Figure S7 Cross-sectional TEM images of (a) 2-layer; (b) 3-layer and (c) 4-layer $\mathrm{MoS}_{2}$ deposited by trickle-flow ALD.

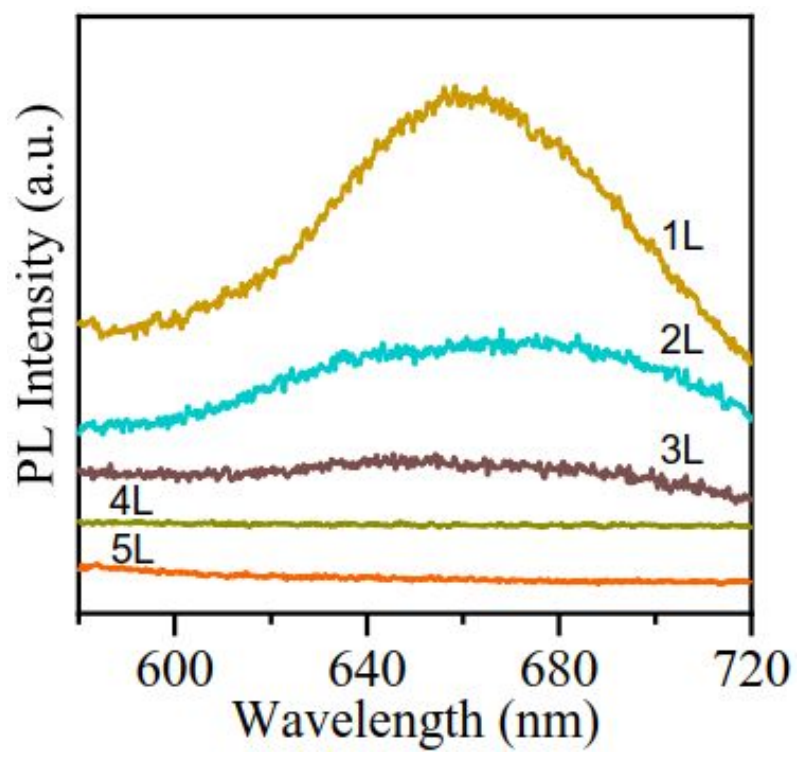

Figure S8 The photoluminescence spectra for as-deposited $\mathrm{MoS}_{2}$ film from 1 to 5 layers. 